\title{
Analysis and development of methods for optimizing the management of repair activities of energy enterprises
}

\author{
Shushanik Militonyan ${ }^{1, *}$, and Petr Shamigulov ${ }^{1}$ \\ ${ }^{1}$ National Research University "MPEI", Power Engineering Department, 404110 Volzhsky, Russia
}

\begin{abstract}
Currently, research and developments in the field of monitoring and diagnostics of equipment of energy enterprises, as well as new approaches in the management of repair activities, have gained high importance. This is due to the increasing mechanism of aging of energy equipment. In the coming years, it is expected to increase the decommissioning of the main production fund, which is used at the limit of capabilities. There is a need for a comprehensive study and systematization of repair performance indicators, the development and improvement of existing methods for assessing the repair activity of equipment. New opportunities are emerging for digital-based research and development. The article considers issues related to the introduction of modern methods for optimizing the management of repair activities of energy enterprises. Theoretical and methodological provisions of existing systems for maintenance and repair of power plant equipment are described. Analysis was carried out, on the basis of which the advantages and disadvantages of these systems and methods of equipment diagnostics were revealed, the model for calculating the repair production factor "unit costs" was presented and considered.
\end{abstract}

\section{Introduction}

At the moment, the relevance of the issue considered in the article is due to the high development requirements outlined in the approved Energy Strategy of Russia State Energy Policy for the Period until 2030 [1], which describes the tasks that will improve the state of the energy sector and its management efficiency. According to the analysis carried out in the field of development of existing methods for optimizing the repair process, the best solution for enterprises, in particular energy enterprises, in terms of automation and digitalization of the process, can be considered complex modular automated systems.

Having reviewed foreign repair management systems, it can be seen that they do not set themselves the task of extending the service life of electrical equipment, since their practice involves only replacing equipment after the end of its service life. There are also serious differences in regulatory documentation for the repair and maintenance, diagnosis, testing, composition of equipment and its operation, which do not allow the use of foreign systems for assessing the technical condition of equipment for Russian power systems. Meanwhile any innovations in any system inevitably encounter a certain internal resistance. As a result the expediency of practical introduction even of the most "effective" technologies becomes very doubtful, and they, in the majority, are the unclaimed world companies. But, if to consider strong influence financial, temporary, organizational, factors, then it is possible to draw a conclusion that at introduction of similar systems which allow to solve problems of management at least of repair activity not less than 3 years will be required. Considering the experience of foreign countries in terms of management technologies based on Russian enterprises, we faced a number of reasonable difficulties. If you look at the very principles and methods of repair management, which are considered effective in the leading countries of the world, repair management systems, you can see that they do not set themselves the task of extending the life of electrical equipment, since their practice involves only replacing equipment after the end of its service life. Currently, research and development in the field of monitoring and diagnostics of power plant equipment have gained great importance. This is due to the growing mechanism of aging of energy equipment. As a result, an increase in the decommissioning of the main production fund, which is used at the limit of capabilities, is expected in the coming years. A comprehensive study and systematization of repair performance indicators, the development and improvement of existing methods for assessing the repair activity of equipment are necessary.

The experience of foreign countries in the field of management technologies is quite high, but using it on the basis of Russian enterprises makes us face a number of reasonable difficulties. During the analysis, serious differences were noted in the regulatory documentation for repair and maintenance, diagnostics, tests, equipment composition and its operation. If you look at the very principles and methods of managing repair activities that are considered effective in leading countries of the world, you can see that for the most part the

* Corresponding author: militonyan_s@mail.ru 
management system needs to be fundamentally changed with the help of strengths, the will and power influence of the leadership. Meanwhile, any innovations in any system inevitably encounter some internal resistance. As a result, the feasibility of practical implementation of even the most "efficient" management technologies is in question, and they are unclaimed by Russian companies.

Existing systems for assessing the technical condition of equipment are automated expert systems. These systems are mainly designed to solve the following problems - analyzing the state of the equipment in order to detect defects and faults, as well as optimizing control actions on control objects in order to increase the reliability of the equipment and extend the life of the objects. In modern conditions, depending on the volume and completeness of data collected, as well as the area of using these data for analysis and technical diagnostics, the following are used:

- mathematical methods;

- logical methods of curve recognition;

- separation methods in the attribute space;

- methods based on probability theory;

- Methods based on information theory;

- statistical methods of recognition;

-methods based on determining the value of characteristics, etc.

For correct operation of the repair management system, we note the importance of the influence of energy characteristics not only on the optimization of the mode of operation of energy equipment, but also on various violations of the normal mode of operation of energy equipment and on its characteristics. Therefore, optimizing the determination of energy characteristics of power equipment is a timely and important task. Consider the current methods used to determine energy characteristics and the global trends towards development. Energy characteristics can be determined by specially organized tests and during normal operation. Depending on the task, the tests are divided into [2]:

- commissioning modes carried out in order to build mode optimal maps of power equipment operation (for example, dependencies of the optimal value of the excess air coefficient on the power unit load);

- mode-information, carried out to determine static characteristics (for example, consumption characteristics and characteristics of specific increments) or to determine the degree of violation of normal operation mode of power equipment (for example, when switching off the air heater, smoke pump or blast fan, etc.);

operation, carried out after overhaul or reconstruction, when switching to another type of fuel, when systematic deviations of parameters from normal values, etc.;

- special ones carried out to identify the characteristics of individual elements of power units (boiler superheater, water economizer, air heater, circulation system, etc.) or to determine their condition;

- acceptance and delivery, carried out in order to check the technical and economic indicators of power equipment guaranteed by the manufacturer.

\section{Analysis of modern existing methods for assessing and optimizing the management of repair activities of energy enterprises}

At the moment, sufficient experience has already been gained in finding various approaches to solving the problem of optimizing repair management, which finds itself in a variety of methods for analyzing equipment failures. Such methods include the following: qualitative method, causative analysis, spatial analysis, Pareto analysis [2], Schuhart control maps, quantitative method, temporal analysis, methods for calculating reliability indicators [3]. Let's look at modern methods of analysis of technical condition of equipment. Let's look at the most well-known methods of assessing the state of equipment, the methods of analysis in more detail.

A qualitative method based on a joint analysis of aggregate data on equipment failures allows you to identify logical patterns of their occurrence. This method is relatively low in data collection, preparation and initial processing, but requires significant intellectual costs, a good knowledge of the equipment and an understanding of its processes for successful application. The conclusion, based on the available data samples, should be made by the specialist himself, and not by the system, which largely depends on his level of expertise.

Causal-factor analysis is the identification of typical problems characteristic of a particular equipment, site, workshop, enterprise as a whole. In order to achieve the result, during the investigated period the number of implementation of accidents due to their causes, repair effects on pitches, replacement of spare parts by types or other similar indicators is determined. The impact of the category with the largest or most sample implementations becomes the basis for making appropriate recommendations.

Spatial analysis is aimed at determining the "weaknesses" of the equipment, process line, plant as a whole. For this purpose, for the period under investigation, the number of incidents implementation at the place of their occurrence is determined for objects of process items that are lower in the hierarchy (for the enterprise - by workshops, for the workshop - by sites, for equipment - by units). Objects that generate the largest or most problems require additional research to form appropriate recommendations.

Temporal analysis is aimed at identifying cyclical patterns of incidents [4-6]. For this purpose, for the study period, which, at the discretion of the researcher, is supposed to include several (if possible, more, but not less than three) cycles, the number of implementations of incidents at given intervals (hours, days of the week, months) is determined. Consideration of extremes allows us to form a hypothesis about the causes of cyclicity (seasonal factors, personnel qualifications of various shifts and the like), which can be the basis for the development of appropriate recommendations in order to minimize the influence of negative factors.

Monitoring, which includes a whole complex that records the maximum amount of information about 
equipment parameters. In the course of data collection and processing, the reliability criterion of power equipment is evaluated, it can be said that it depends not only on the quality of production, but also on theoretically and scientifically justified operation, identification of the type and degree of danger of a defect at an early stage of its development, forecasting the service life or residual life of the equipment, correct maintenance, as well as timely repair. Data from the system analysis of information on the state of modern power equipment show that fairly high design reliability indicators have been achieved. This does not exclude the fact that during operation under the influence of various factors, conditions and modes of operation, the initial condition of the equipment is constantly deteriorating, operational reliability is reduced and the risk of failures increases. The process of equipment operation is based on sequential changes in the time of operation, reserve, repair, maintenance, etc.

By comparing the monitoring system and the various data analysis systems applied worldwide, some advantages of the monitoring system can be identified:

- monitoring, carried out in process mode;

- data reliability - high;

- storage of output data allows to identify dependencies and relationships between occurring events during operation;

- possibility to diagnose electrical equipment under voltage.

If we consider the monitoring system for assessing the state of electrical equipment and determining the assessment of the state of substation equipment, we note the disadvantages:

- output information, requires the mandatory availability of a mathematical apparatus with a program description, for its further processing and analysis;

- the monitoring system practically does not include a final set of data on the entire equipment of the existing facility, it is used to monitor the main nodes, very rarely for auxiliary equipment.

Existing information collection and processing systems allow to take into account some shortcomings in existing methods of equipment repair and maintenance. [6] Today, technical diagnostics and testing methods are also actively used to assess the state of equipment at power plants and substations. Periodicity and scope of diagnostics are regulated. The number, type, value, and methods of data collection vary depending on how the equipment is diagnosed and assigned. Any type and type of equipment implies the existence of a method of nondestructive testing (testing), by which it is possible to obtain data on the state of equipment with a frequency of inspection at least once a year. This method allows you to have retrospective information about equipment state parameters, which allows you to not only monitor the dynamics of these parameters, but also on the basis of its analysis to predict possible failures and defects.

The main factors affecting the reliability of the equipment, except for the time factor (on-work), include parameters that determine the operation of the resource. At the same time, even for the same type of equipment (for example, electrical equipment: electric motors, switches and transformers), an uneven operation of the resource is characteristic. This indicates that the impact of operational factors on the technical condition must be taken into account when determining the equipment repair needs. Therefore, the generalized model of resource consumption should be specified depending on the peculiarities of operation, repair and operation modes of specific types of equipment.

In the power industry, to carry out production operation and maintain the correct technical condition of the equipment in accordance with the requirements of the regulatory and technical documentation [7], a planned preventive repair system is also used (hereinafter - PPR). In many ways, the existing PPM system has effectiveness, but it does not always ensure effective decision-making.

\section{Search for optimization opportunities, taking into account the analysis of the identified advantages and disadvantages, their application on the example of an automated system for monitoring the technical condition of a dispersed energy facility}

After considering in more detail the process of creating and developing equipment diagnostics systems, we can note the progress of several stages, we will consider the main ones. At the first stage, standard sensors, devices and devices are used. Further, they are supplemented by missing sensors, specialized means. At the next stage, as information systems develop, an automated system for monitoring the technical condition (ASKTS) of equipment is created on the basis of these tools. It, in turn, successively develops into the subsystem of the APCS of the energy facility as a whole and then into a regional and industrial system [8]. Structural diagram of configuration of such a complex of ASKTS hardware is given in Figure 1. 


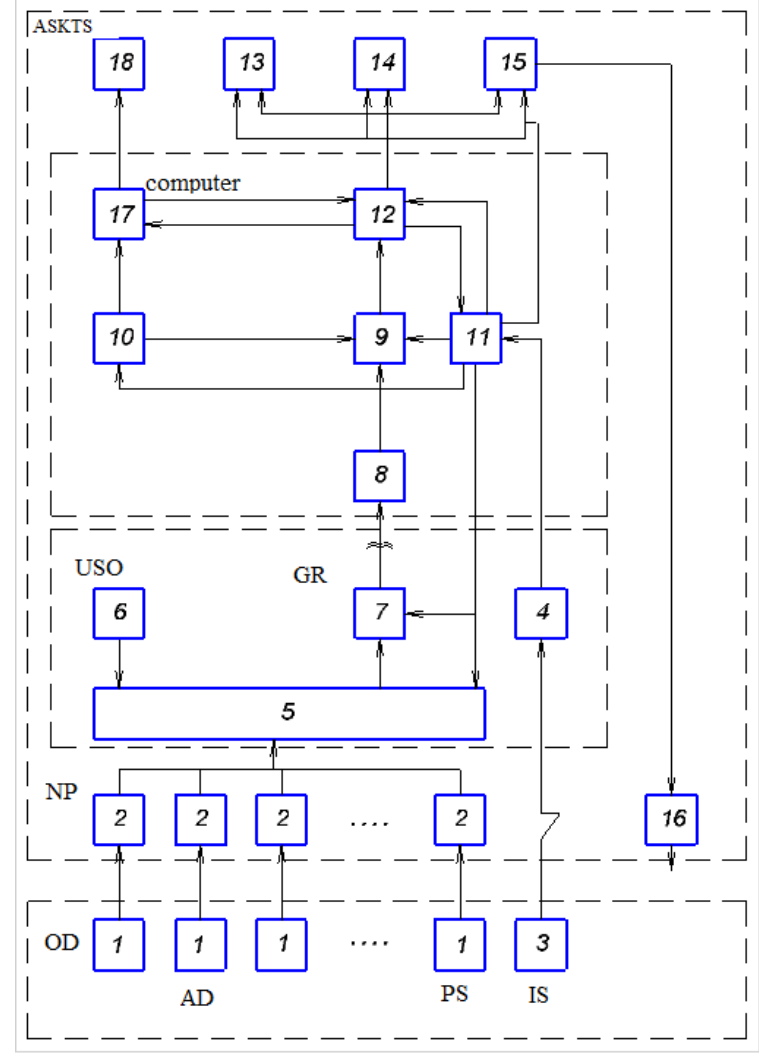

Fig. 1. Block diagram of an automated system for monitoring the technical condition of equipment of a dispersed power facility.

Within each type, methods are still classified according to different additional characteristics. For example, sensors are installed at the diagnostic facility (OD), the composition and number of which are determined by the tasks of ASKTS and the number of monitored electrical equipment.

In order to take into account the large volume of data of different origin, in a complex information environment, it is necessary to consider in aggregate, simultaneously considered criteria. This structure can be represented in the form of interaction of individual subsystems: data generation, collection, generation of knowledge, decision making, conclusion. The database generates and stores almost all information about the object, various data on previously carried out diagnostics and monitoring.

From the technical and economic point of view, the indicator "unit costs," where repair and maintenance per unit, is most accurately reflected in the efficiency of repair work [9]. Based on the initial analysis of information on repair activities based on diagnostics and monitoring in the current conditions of development and digitalization, it was considered, as an assessment of the efficiency of repair production, in the first phase of research, Consider, by means of a generalized analysis, the calculation of an indicator that will be able to compare productivity growth and the cost of achieving it, in the future, other indicators and some optimization and efficiency methods can be considered. Recommendations for calculation and system analysis of the "unit costs" indicator are presented below:

$$
Z_{\text {sum }}^{\text {ud }}=\frac{Z_{\text {sum }}}{E R S}
$$

where $-Z_{\text {sum }}^{\text {ud }}-$ total costs associated with the maintenance and operation of equipment, p/pcs.; $Z$ - total costs associated with the maintenance sum

and operation of this equipment, p.; ERS - unit of equipment repair complexity [13].

All equipment used at the enterprise is reduced to a general type (to the simplest form), and a conventional unit of equipment repair complexity is considered as an indicator to achieve real comparison conditions.

According to the proposed methodology, to bring all equipment to the simplest form, it is necessary to use coefficients that take into account different ratios of repair costs depending on the type of complexity, age and equipment load.

$$
\sum U E=\sum K \cdot K 1 \cdot K 2 \cdot \mu
$$

where $\sum U E$ - the total number of conventional units of the repair complexity of a specific type of equipment at the enterprise, adopted in the PPR system; $\sum K$-the total number of units of repair complexity for this type of equipment; $\mathrm{K} 1$ is a coefficient that determines the different level of material costs for models of one type of equipment, depending on the repair complexity; $\mathrm{K} 2$ is a coefficient that takes into account different levels of material costs depending on the age of the equipment; load factor of a certain type of equipment.

Using these coefficients allows you to calculate the total number of conventional units of repair complexity of all equipment at the enterprise:

$$
U E=\sum_{1}^{n}\left(\sum U E\right) \cdot K 3
$$

where K3 - coefficient that determines the level of costs for materials, depending on the type of equipment.

According to the above methodology, the quantitative values of the coefficients used in (2) and (3) are calculated on the basis of an analysis of the economic indicators of the activities of the repair services at the enterprise. Substituting the indicators into the general formul (1), we get:

$$
Z_{\text {sum }}^{u d}=\frac{Z_{\text {sum }}}{U E}
$$

where UE - the number of conventional units of repair complexity of all types of equipment at the enterprise, pcs. 
Thus, it is advisable to develop an automated system for monitoring parameters and processing information to assess the state and predict the reliability of equipment, as well as the need to develop new methods of operational control over operating modes and the main influencing factors on equipment and special technical means of control [10]. In this case, statistical data will be formed based on the results of observations of equipment carried out during operation during testing, maintenance and repair.

\section{Conclusion}

As a result of the studies carried out, the analysis of existing methods for assessing and optimizing the management of repair activities of energy enterprises was carried out, a recommendation was proposed on a generalized model of the method for assessing the indicator of the effectiveness of repair activities from a technical and economic point of view at the enterprise and a conventional unit of equipment repair complexity, which allows to analyze the operation of an enterprise; it also allows taking into account the type, load, complexity and age of the equipment. The possibility of applying the results obtained in the context of the development and implementation of digital technologies in the energy industry is analyzed [11-13]. An analysis was carried out in the field of ensuring the reliability of the operation of the main and auxiliary equipment of power plants, which showed that this problem from the point of view of the optimal organization and effective functioning of the system of technical and repair service according to the technical condition is not fully reflected in them. At the next stage of research, it is planned to determine the relationship between the indicators of the technical condition of power equipment and its operational reliability, to analyze the identified applied and most promising developed methods of diagnostics and monitoring, existing regulatory and technological documents necessary for the transition from the PPR system to the most promising system of technological maintenance and repair according to the actual condition of equipment. It is also proposed to carry out studies to assess the influence of the uncertainty of information on the technical condition of electrical equipment on the accuracy of determining the indicators of operational reliability and the frequency of repairs.

The research is funded by Russian Federation public contract № FSWF-2020-0025 "Technique development and method analysis for ensuring power system object security and competitiveness based on the digital technologies".

\section{References}

1. Energy strategy of Russia for the period up to 2030, Approved by the order of the Government of the Russian Federation, 1715-r (13 November 2009)

2. E.M. Nekrasova, Current trends and prospects for the development of energy in Russia, Materials of the XLVII International Conference "Student and Scientific and Technological Progress": Economics, Novosibirsk State University Novosibirsk, 0.1 (2009)

3. D. William, Goldratt's Theory of Constraints: A Systems Approach to Continuous Improvement (M.s Alpina Business Books, 444, 2008)

4. A. Lamarche, P. Samson, Development of an equipment maintenance management support system, International Oil Spill Conference Proceedings, 1, 453-457 (2008)

5. J. Chen, M. Hagiwara, Development of a maintenance management support system based on a Hierarchical Fault Classification, International Journal of Industrial Engineering, 7 (3), 255-264

6. S. Shimizu, Y. Ando, T. Morioka, Development of maintenance management support system for nuclear power plant based on study of equipmentlife estimation technique, Journal of the Atomic Energy Society of Japan, Atomic Energy Society of Japan, 31 (10), 1144-1157 (1989) DOI: 10.3327/jaesj.31.1144

7. GOST 27.503-81, Reliability in technology, Information collection and processing system, Methods for assessing reliability indicators, The Russian State Standard

8. A.N. Nazarychev, G.K. Voronovsky, I.V. Nedin (eds.), Basic principles of a new technology for organizing repair maintenance of electrical equipment according to their technical condition, Innovative development of the fuel and energy complex: problems and opportunities (Scientific publication, Kiev: Knowledge of Ukra's, 169-181 (2004)

9. M.S. Ivanitckii, M.M. Sultanov, V.M. Trukhanov, Analysis of the influence of operating modes of heat generating plants on the energy and environmental safety of thermal power plants, Proceedings of the 2nd 2020 International Youth Conference on Radio Electronics, Electrical and Power Engineering, REEPE 2020, 9059205 (2020)

10. A.N. Nazarychev, Methods and models of optimization of repair of electrical equipment of power facilities taking into account technical condition (Ivan. state ener. un-t., Ivanovo, 168, 2002)

11. R.B. Ivut, V.S. Kabakov, Economic efficiency of machinery and equipment repair (Minsk: Belarus, 207, 1988)

12. M.M. Sultanov, A.A. Konstantinov, M.S. Ivanitckii, Environmental aspects of thermal power equipment operation modes optimization, International Journal of Hydrogen Energy, 42 (18), 13300-13306 (2017)

13. B.D. Sparling, A.I. Tadjibaeva, V.N. Osotova (eds.), Increasing the level of monitoring and diagnostics to optimize the transmission and 
distribution of electricity in order to improve financial performance, Methods and tools for assessing the state of power equipment, $\mathrm{SPb}$., 28, 178-202 (2005). 